\title{
Developmental Aspects of Renal $\beta$-Amino Acid Transport II. Ontogeny of Uptake and Efflux Processes and Effect of Anoxia
}

\author{
RUSSELL W. CHESNEY (41) and DIANE K. JAX \\ Pediatric Renal Disease Laboratory, Department of Pediatrics, The University of Wisconsin Center for Health \\ Sciences, Madison, Wisconsin USA
}

\section{Summary}

Renal cortex slices from newborn, 2-week, and 4-week-old Sprague-Dawley rats had reduced initial rates of taurine uptake compared io adult slices after short $(<30 \mathrm{~min}$ ) incubation periods. From birth onward, steady-state accumulation occurred by at least two sodium-dependent uptake systems. The first system had an "apparent $\mathrm{Km}_{1}$ " $=0.1 \mathrm{mM}$ and a Vmax varying from 1.8 to 5.1 $\mu$ moles $/ \mathrm{ml} \mathrm{ICF} / 120 \mathrm{~min}$ at four ages. The second uptake mode had an apparent $\mathrm{Km}_{2}=12-16 \mathrm{mM}$ and a $V \max$ of $45 \mu \mathrm{moles} / \mathrm{ml}$ $I C F / 120 \mathrm{~min}$. Efflux of taurine was reduced in slices from younger animals possibly accounting for taurinuria. Only other $\boldsymbol{\beta}$-amino acids inhibited accumulation.

Anoxia inhibited uptake at high concentrations $(>1.0 \mathrm{mM})$ at each age, but taurine accumulation at low concentrations $(<0.4$ $\mathrm{mM}$ ) was relatively protected from anoxia in neonatal $(<36 \mathrm{hr}$ of age) tissue. Preincubation in taurine-free medium for $120 \mathrm{~min}$ enhanced low concentration, but not high concentration uptake in neonatal and 2-week slices.

After preincubation in dibutyryl cyclic AMP (dbcAMP) enhanced uptake of taurine was found in adult cortex, but not in neonatal cortex.

The ontogeny of renal taurine transport in cortex slices appeared to involve faster initial uptake rates and faster efflux as well as greater dependence on aerobic metabolism with maturation. Age-related differences in the response to preincubation and cyclic nucleotides were also indicative of maturational events in renal tubular amino acid transport.

\section{Speculation}

Taurinuria found in the immature rat may involve decreased initial uptake rates and/or decreased efflux, but heterogeniety of transport processes across the antiluminal membrane was apparent at birth. Preincubation in taurine-free medium increased the rate of taurine accumulation by immature cortex, but changes in transport processes across the brush border membrane may account for the decrease in taurinuria found after the age of 2 weeks.

Heterogeniety of taurine transport into adult Sprague-Dawley rat cortex slices was found $(7,8)$. The first uptake system had an apparent $\mathrm{Km}$ of $0.1-0.2 \mathrm{mM}$ and the second system values of 13$15 \mathrm{mM}$, akin to those concentrations found in the mouse (9). The first site is saturable and could serve to facilitate transport in the concentration range of taurine found in rat plasma, 200-400 mmole/liter $(2,9)$. The second transport site is similar to the nonsaturable taurine transport system found in Erhlich ascites cells and rat jejenum by Christensen et al. (10). Baerlocher et al. (3-5) have previously shown that the various transport systems for glycine and iminoacid transport appear at different ages in newborn Long-Evans rat pups and further that the high $\mathrm{Km}$, low affinity system for $\alpha$-aminoisobutyric acid ( $\alpha$-AIB) uptake was missing until 3 weeks of age (3-5). Segal and associates (20, 23, 27) have been unable to confirm the finding that transport systems emerge with age using both Sprague-Dawley and Long-Evans rats (24). The pattern of transport processes for taurine accumulation in slices from immature and adult animals would obviously be informative in view of the increased taurinuria of young animals described in the preceding paper (9).

Other studies demonstrated that the initial rate of uptake was reduced in neonatal tissue and might account for aminoaciduria $(3-5,27,28,33,34)$. Further, the rate of exit (efflux) of a wide variety of $\alpha$-amino acids from immature animal cortex slices is diminished thereby permitting the back-flux of these substances from an expanded intracellular pool into the urinary space (3-5, $27,28,33,34)$. We have previously shown that in vivo taurine tissue levels are higher in cortex slices from newborn animals than in slices from adult animals (9) as would be expected were slower efflux present. Furthermore, the in vivo tissue to plasma ratios are higher in tissue from newborn, 2-week, and 4-week-old animals.

Taurine accumulation by adult rat and mouse slices is sodiumdependent at both transport sites and only other $\beta$-amino acids, of all amino acids examined, inhibited the uptake of taurine in a competitive fashion at both sites (7-9). Thus, an examination of these conditions is germaine. In adult cortex, amino acid uptake was almost entirely dependent on aerobic metabolism; taurine accumulation also required aerobic metabolism (7-9). Concentrative uptake was not totally abolished by an aerobiosis in tissue from newborn animals. Baerlocher et al. (5) showed that proline and glycine uptake by immature animal slice could better withstand incubation under anoxic condition or in the presence of cyanide. Incubation of immature animal tissue with cyanide to block oxidative metabolism, iodoacetate to block glycolysis, and in a nitrogen atmosphere may also provide information concerning the ontogeny of taurine transport.

Preincubation of tissue from immature animals, rat uterus (21), chick embryo heart (11), placenta (12), and rat renal cortex (20) in a medium containing only buffer and devoid of the substrate to be transported has been shown to enhance the uptake of amino acids. Reynolds and Segal (21) found that $\alpha$-AIB uptake was increased at least 2 -fold by preincubation in media at $37^{\circ} \mathrm{C}$, but not at lower temperatures or with anaerobiosis. These findings have led us to determine that similar preincubation will enhance taurine accumulation as well.

Preincubation in a medium containing cyclic nucleotides, particularly dbcAMP, which is readily permeable through plasma membranes, led to enhanced rat renal cortex slice uptake of $\alpha$ AIB and lysine $(17,35)$. A similar enhancement of $\alpha$-methyl-Dglucoside accumulation by renal cortex was reported by Rea and 
Segal (19). We have chosen to examine this effect in newborn and adult animal slices to look for any age-related changes.

\section{METHODS}

\section{PREPARATION OF TISSUES}

Kidneys were obtained from Sprague-Dawley rats $(36,37)$ of the following ages: newborn (within $36 \mathrm{hr}$ of birth), 2-week, 4week, and adult. Thin cortex slices were prepared as previously described (7-9) and cortex slices were made from newborn and 2week-old animals using only the surface of the kidney. By examination under a microscope, these slices contained only cortex cells. Slices from the kidney of several newborn animals (generally from a litter of 8-10 pups) were used in incubation studies. Slices were approximately $5 \mathrm{mg}$ in weight and were cleanly cut with a razor blade to provide straight edges. No discrimination was made between male and female newborn animals; thereafter, only male rats were used.

\section{TISSUE INCUBATION}

Tissue was incubated as described (7-9) and a Tris-Ringer glucose medium was used as described before (6). Slices were removed, blotted, weighed, boiled, and the supernate counted as described $(7,8)$. The medium was altered in several ways for certain studies: choline or potassium choloride were substituted for $\mathrm{NaCl}$ in a stepwise fashion so as to maintain constant osmolality. Sodium cyanide $\left(10^{-2} \mathrm{M}\right)$ and iodoacetate $\left(3 \times 10^{-3} \mathrm{M}\right)$ were added to the medium. Incubation with other amino acids was performed using 10 times the final taurine concentration in the medium and representative compounds from each amino acid class were used.

\section{EFFLUX STUDIES}

The exodus of intracellular taurine from slices was by the method of Segal et al. (26). Slices from animals of various ages were incubated for 60 or $90 \mathrm{~min}$ in taurine containing medium until comparable tissue taurine levels were achieved. Tissue was then removed, blotted, weighed, and placed in substrate-free medium. Samples of medium were removed every $2 \mathrm{~min}$ up to 16 min and the rate of appearance of taurine into the medium and the final tissue taurine levels were measured. Efflux over the first 2 min was not examined.

\section{PREINCUBATION AND DIBYTYRYL CAMP INCUBATION}

Preincubation studies were performed in a manner similar to that described by Reynolds and Segal (21). Half the slices from one adult, two 4-week, four 2-week, and a litter of newborn animals were placed in conventional medium devoid of taurine under $\mathrm{O}_{2}$ at $37^{\circ} \mathrm{C}$. After 120 min preincubation, slices were rinsed in $0.154 \mathrm{M} \mathrm{NaCl}$, blotted, and placed in the test medium containing taurine. The remaining slices were not preincubated, but were incubated immediately in taurine-containing medium as described above. The influence of preincubation on the efflux of taurine was examined by measuring this efflux in tissues incubated in taurine for $90 \mathrm{~min}$ after a preincubation period of $120 \mathrm{~min}$. Again, half the tissue was directly incubated in a taurine containing medium for $90 \mathrm{~min}$ and then used for efflux studies.

Studies of the influence dbcAMP on uptake were performed in two different fashions. Cortex slices were incubated in medium containing either with or without $1 \mathrm{mM}$ dbcAMP for $60 \mathrm{~min}$ at $37^{\circ}$ at which time uptake distribution ratios were determined. In other experiments, cortex tissue was preincubated in media either with or without $1 \mathrm{mM}$ dbcAMP for $120 \mathrm{~min}$ at $37^{\circ} \mathrm{C}$. Slices were then washed, blotted, and placed in flasks containing taurine for uptake incubation studies and dbcAMP ( $1 \mathrm{mM})$ was present in the final incubation mixture in half of the flasks.

\section{ANALYSIS}

All slice experiments were performed in triplicate and data were compared using the Student's $t$-test.

Corrected values for uptake on more than one system was obtained by the methods of Scriver and Mohyuddin (25) and Neal (16). Analysis of uptake kinetics were performed under steadystate conditions unless otherwise indicated.

\section{MATERIALS}

$\left[1-{ }^{14} \mathrm{C}\right]$ Taurine (Spec act $56.1 \mathrm{mCi} / \mathrm{mmole}$ ) was obtained from New England Nuclear (38). Unlabeled amino acids, iodoacetate, sodium cyanide, and dbcAMP were purchased from Sigma Chemical Company (39) and were of reagent grade. All chemicals used to prepare media were of the purest quantity obtainable.

\section{RESULTS}

\section{INITIAL RATE OF UPTAKE}

Initial uptake isotopic distribution ratios after short periods of incubation ( $<30 \mathrm{~min}$ ) with taurine, at four concentrations varying from $0.01-20 \mathrm{mM}$, were lower in renal cortex slices from rat pups of 1 day, 2 weeks, and 4 weeks of age when compared to adult slice values (Fig. 1). The uptake of taurine at a high concentration, $20 \mathrm{mM}$, was similar in 4-week and adult cortex slices, but uptake in slices from younger animals was always slower. These findings suggest that the postnatal development of taurine transport involves an acceleration in the rate of uptake over a wide range of concentrations.

\section{CONCENTRATION DEPENDENCY}

When accumulation for $120 \mathrm{~min}$ was examined over a broad spectrum of concentrations, $0.001-60 \mathrm{mM}$, the uptake distribution ratio fell as the substrate concentration was raised. Steady-state uptake did not follow simple Michaelis kinetics throughout the concentration range. A Lineweaver-Burk plot (Fig. 2) and an Eadie-Augustinson transformation (Fig. 3) of the data revealed that both systems found in adult tissue were present at birth. The derived $\mathrm{V} v s$. $\mathrm{V} / \mathrm{S}$ regression plot was biphasic at all ages, indicating evidence for more than one mode of uptake. At initial medium concentrations (less than $0.4 \mathrm{mM}$ ), tissue from immature animals achieved very high distribution ratios and $\mathrm{V}$ max values were higher (vide infra), but uptake at initial concentrations greater than $0.4 \mathrm{mM}$ is greatest in adult tissue. Uptake by 2- and 4-weekold animal cortex slices was also greater at initial taurine levels

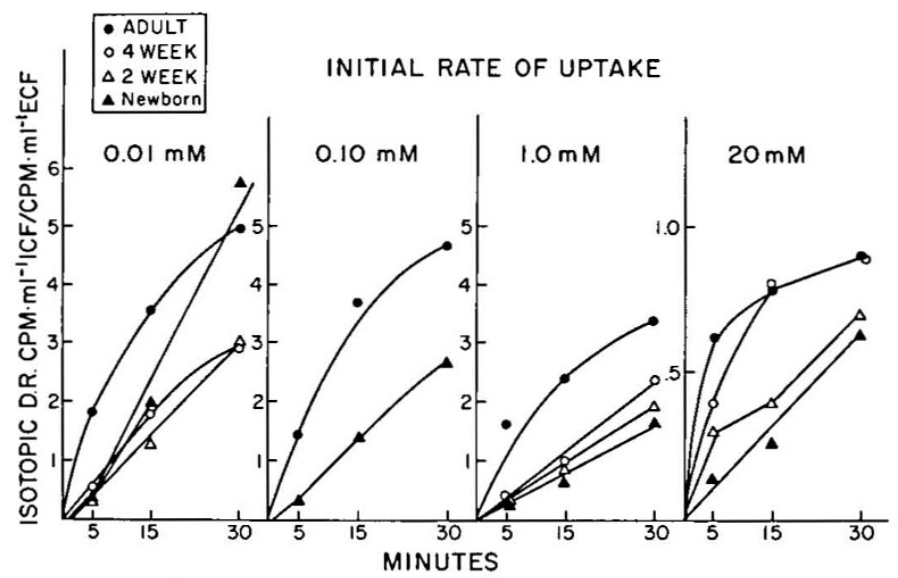

Fig. 1. The early time course for uptake for taurine at low and high concentrations in the initial medium. The isotopic distribution ratio (D.R.) represents counts $/ \mathrm{min} / \mathrm{ml}$ intracellular fluid: counts $/ \mathrm{min} / \mathrm{ml}$ of incubation medium. Each point is the mean of at least six observations. The symbols for each age are shown in the inset. 


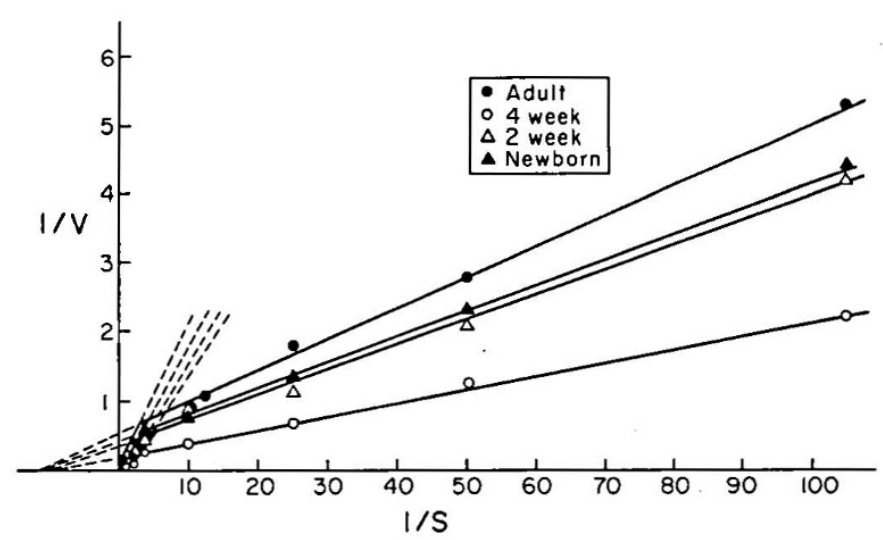

Fig. 2. Lineweaver-Burk plots of taurine uptake by rat kidney cortex slices of the ages shown. These plots are indicative of more than one uptake process. The apparent $\mathrm{Km}_{1}=0.1 \mathrm{mM}$ and the apparent $\mathrm{Km}_{2}=$ 12-16 mM for all ages. Slices were incubated for $120 \mathrm{~min}$ in Tris-Ringer glucose medium $(\mathrm{pH} 7.4)$ at $37^{\circ} \mathrm{C}$. Each point is the mean of 18 slices.

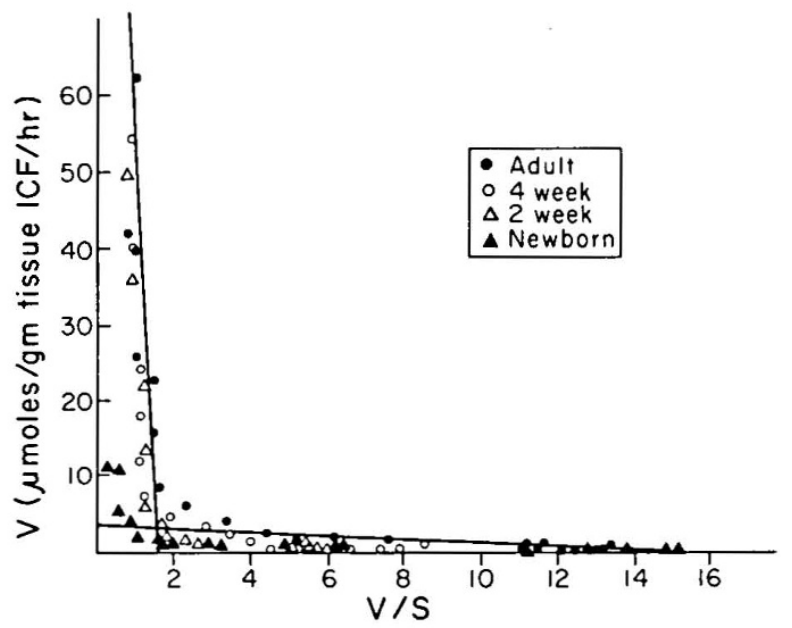

Fig. 3. Concentration-dependent kinetics for taurine uptake by rat cortex slices examined over a 400 -fold variation in substrate concentration. The Eadie-Augustinson transformation reveals at least two modes of transport at each age indicating that both systems are present at birth. Data are composites of more than 500 determinations over the entire range of initial taurine concentrations.

$<0.4 \mathrm{mM}$, but is identical to levels found in adult tissue at the second or high concentration site.

The derived affinity constants at each age were approximately $0.1 \mathrm{mM}$ for the first system and $12-16 \mathrm{mM}$ for the second system. Maximal rates (V max) for transport on the low-Km system varied from $1.8 \mu$ mole uptake/ml intracellular fluid/120 min in adult tissue to $5.1 \mu$ mole in tissue from 4-week-old animals (Table 1). The maximal rate on the second system was approximately 45 $\mu \mathrm{mole} / \mathrm{ml}$ intracellular fluid/unit time. As shown in the preceeding paper, steady state at high initial taurine concentrations was achieved earlier in adult tissue. Therefore, these studies were carried out for at least $120 \mathrm{~min}$ so that steady state values could be determined (32).

\section{EFFLUX}

Slices preloaded with taurine at 0.01 and $1.0 \mathrm{mM}$ were placed in taurine-free medium for $16 \mathrm{~min}$ at $37^{\circ} \mathrm{C}$. Efflux of taurine at each concentrations was impaired in immature tissue and the rate of exit increased with age after birth (Fig. 4). This decreased efflux possibly accounted for the very high tissue distribution ratios found for steady-state uptake at $0.01-0.1 \mathrm{mM}$ by immature rat tissue.

\section{INHIBITION OF UPTAKE}

Uptake of taurine in slices from immature animals of all ages, similar to the findings in adult animal tissue (6), was sodiumdependent. Removal of sodium from the external medium with the substitution of choline or potassium in a serial fashion resulted in progressive inhibition of taurine accumulation each age. Choline or potassium concentrations of $112 \mathrm{mM}$ and sodium levels of $28 \mathrm{mM}$ were associated with the loss of concentrative uptake. The values for the complete substitution of sodium by choline are shown in Table 2.

Ten-fold higher concentrations of glycine, leucine, cysteine, glutamic acid, and tyrosine altered taurine uptake by less than $10 \%$ of control values in amino acid free media (range $92-109 \%$ of control values). $\beta$-alanine at 1 and $5 \mathrm{mM}$ prevented concentrative taurine accumulation at each age in slices incubated at $0.01 \mathrm{mM}$

Table 1. Maximal rates ( $V$ max) for transport of taurine in newborn, immature, and adult cortex slices ${ }^{1}$

\begin{tabular}{lc}
\hline Age & $\mathrm{V} \max (\mu \mathrm{mole} / \mathrm{ml}$ intracellular fluid/120 min $)$ \\
\hline Newborn & 2.5 \\
2 week & 2.9 \\
4 week & 5.1 \\
Adult & 1.8 \\
\hline
\end{tabular}

1 The derived $\mathrm{V} \max$ for the saturable first component of uptake was ascertained from the Michaelis equation using data from the range $0.001-$ $2.0 \mathrm{mM}$. Incubation times were $120 \mathrm{~min}$ and approximately 18 determinations were made at each concentration at each age.

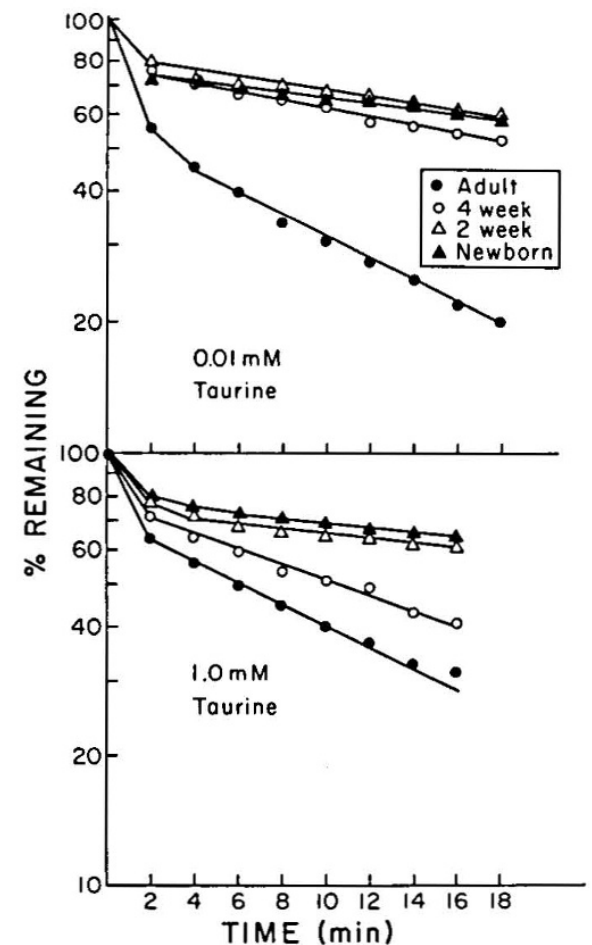

Fig. 4. Efflux of $\left[1^{-14} \mathrm{C}\right]$ taurine into $\mathrm{pH} 7.4$ Tris-Ringer medium free of taurine at $37^{\circ} \mathrm{C}$ at low (above) and high (below) concentrations from rat kidney cortex slices preloaded with taurine for 60 or $90 \mathrm{~min}$ so that efflux took place from intracellular taurine concentrations that were comparable in immature and adult tissue. The efflux of taurine is impaired in immature tissue. Data are the mean of at least nine determinations at each point and the symbols for each age are shown in the inset. 
Table 2. Influence of choline substitution for sodium on taurine isotopic distribution ratio ${ }^{1}$

\begin{tabular}{clrrrr}
\hline Taurine $(\mathrm{mM})$ & & Adult & 4 week & 2 week & Newborn \\
\hline 0.01 & $\mathrm{NaCl}$ & $11.4 \pm 0.6(n=16)$ & $8.6 \pm 0.6(n=8)$ & $4.8 \pm 0.4(n=8)$ & $7.5 \pm 0.8(n=16)$ \\
0.01 & Choline Cl & $0.8 \pm 0.1(n=16)$ & $1.2 \pm 0.1(n=8)$ & $0.8 \pm 0.1(n=8)$ & $0.7 \pm 0.3(n=8)$ \\
2.11 & $\mathrm{NaCl}$ & $3.4 \pm 0.2(n=16)$ & $2.9 \pm 0.3(n=8)$ & $1.7 \pm 0.3(n=8)$ & $1.3 \pm 0.3(n=8)$ \\
2.11 & Choline Cl & $0.8 \pm 0.1(n=16)$ & $0.9 \pm 0.1(n=8)$ & $0.8 \pm 0.1(n=8)$ & $0.5 \pm 0.2(n=8)$ \\
\hline
\end{tabular}

${ }^{1}$ Renal cortex slices were incubated with medium and taurine at $37^{\circ} \mathrm{C}$ and $\mathrm{pH} 7.4$ under $100 \% \mathrm{O}_{2}$ for 60 min. Each value is the mean $\pm \mathrm{SD}$ of the data $(n=$ No. of experiments).

${ }^{2}$ The $P$ value between $\mathrm{Na}^{+}$containing medium and choline containing medium at each age is $<0.01$.

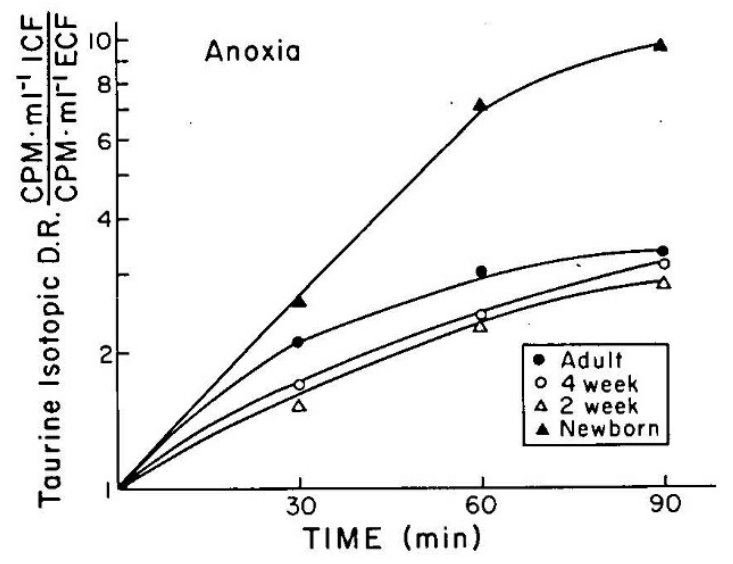

Fig. 5. Effect of anoxia on the accumulation of taurine at $0.01 \mathrm{mM}$ in the initial medium for the times shown. The ordinate shows the taurine isotopic distribution ratio and each point is the mean of 15 determinations. Taurine accumulation persists despite anoxia in slices from newborn animals, but is not as great as that found in the presence of oxygen.

and $10 \mathrm{mM} \beta$-alanine prevented concentrative uptake at $1.0 \mathrm{mM}$ taurine at each age. $\beta$-aminoisobutyric acid at 10 and $20 \mathrm{mM}$ also inhibited taurine uptake at 0.01 and $1.0 \mathrm{mM}$. Therefore, the integrity of the $\beta$-amino acid transport system was intact at birth.

\section{EFFECT OF ANOXIA}

Tissue slices from animals of all ages were incubated under $100 \% \mathrm{~N}_{2}$ for times up to $90 \mathrm{~min}$. At $0.01 \mathrm{mM}$, the uptake of taurine was significantly greater in tissue from newborn animals than at any other age $(P<0.001)$ (Fig. 5$)$. Nonetheless, accumulation by neonatal cortex was only approximately $50 \%$ of that found when tissue was incubated under $100 \% \mathrm{O}_{2}$. Furthermore, concentrative uptake by the first affinity system in the presence of $10^{-2} \mathrm{M} \mathrm{NaCN}$ or $3 \times 10^{-3} \mathrm{M}$ iodoacetate was preserved in tissue from immature animals, although not completely (Table 3). This accumulation despite anaerobic conditions did not hold at initial taurine concentrations of $1.0 \mathrm{mM}$ or higher where taurine accumulation was the same at all ages and was always less than by oxygenated tissue, $(P<0.001)$. At higher taurine levels, no age differences were noted in accumulation in the presence of $\mathrm{NaCN}$ or iodoacetate. Thus, the second accumulation system in the newborn animal was more sensitive to anaerobic conditions.

\section{PREINCUBATION}

Taurine uptake by cortex slices from newborn and 2-week-old pups was enhanced by a preliminary incubation of the slices in taurine-free incubation medium for $120 \mathrm{~min}$ at $37^{\circ} \mathrm{C}$ (Fig. 7). Only uptake at $0.01 \mathrm{mM}$ initial taurine concentration is influenced by this preliminary incubation step; uptake at $1.0 \mathrm{mM}$ was unchanged. Indeed, the uptake at an initial concentration of $1.0 \mathrm{mM}$ by slices from adult or 4-week-old animals is significantly lower after this preincubation step.

A kinetic examination of this preincubation phemenona reveals that the initial rate of uptake on the first affinity system was increased in slices from newborn and 2-week-old animals. No differences in the rate of exit between tissue preincubated in taurine-free medium and control slices were evident.

\section{CYCLIC NUCLEOTIDES}

Slices from adult cortex accumulated taurine to a significantly higher level when the slices were preincubated for $120 \mathrm{~min}$ in a medium containing $1.0 \mathrm{mM}$ dbcAMP (Fig. 8a). This effect of dbcAMP was evident for taurine uptake at both 0.01 and $1.0 \mathrm{mM}$, but no effect was found when the preincubation medium contains no dbcAMP or when taurine and dbcAMP were incubated together wihtout a preincubation step (not shown). A distribution ratio of 30 was achieved with the presence of the cyclic nucleotide in both the preincubation and incubation medium when taurine was accumulated from a medium containing $0.01 \mathrm{mM}$ taurine.

In contrast, preincubation with dbcAMP did not appear to augment taurine uptake by tissue from neonatal animals (Fig. 8b). Therefore, it is possible that the maturational changes in taurine transport include the development of that component of the transport process that is sensitive to incubation with cyclic nucleotides.

\section{DISCUSSION}

Newborn Sprague-Dawley rat pups excreted large quantities of taurine in their urine, approximating $46 \%$ of the filtered load at age 2 weeks (6). As has been shown for glycine, imino acids, other neutral $\alpha$-amino acids, lysine, and $\alpha$-AIB $(3-5,20,23,27,28,33$, 34 ), a pattern of maturation of the renal transport system was apparent. Between 2 and 4 weeks of age, taurine reabsorption increased despite a rise in glomerular filtration rate from 0.27 to $2.45 \mathrm{ml} \mathrm{min}{ }^{-1}$ with the result that the fraction of filtered load excreted in the urine fell to $5 \%$. This excessive neonatal taurinuria did not appear to represent the delayed appearance of a specific transport system as had been shown by the studies of Baerlocher et al. (3-5) for glycine, proline, and $\alpha$-AIB. Both transport systems for taurine accumulation were present at birth. This finding of heterogeniety of taurine uptake in animals of all ages examined, with entirely comparable derived affinity constants for each transport system, implied that the basic process for the transfer of this $\beta$-amino compound across the antiluminal membrane was not altered in the immature animal. Further evidence of the presence of both transport systems by birth was the finding that sodiumdependency and inhibition by other $\beta$-amino acids only were characteristics of tissue from neonatal rat cortex. This inhibition by choline substitution and by $\beta$-alanine or by $\beta$-amino-isobutyric acid occurred on both transport systems at all ages.

It is important to recognize that the assignment of $\mathrm{Km}$ values for each uptake process is fraught with difficulties $(14,16,24,25$, 32) because radiolabeled taurine is being accumulated by a tissue pool (presumably the slice intracellular fluid space) containing unlabeled or "cold" taurine. With time, labeled and unlabeled taurine will mix, so that under steady-state conditions, backflux of both molecular species, will occur at different concentrations. Hence, unidirectional flux is not being measured and a $\mathrm{Km}$ for uptake cannot be assigned. Furthermore, net uptake $\mathrm{Km}$ values can only be determined if the $\mathrm{Km}$ efflux is known. Accordingly, the Michaelis equation and Eadie-Augustinson transformation 
Table 3. Influence of $\mathrm{NaCN}\left(10^{-2} \mathrm{M}\right)$ and iodoacetate $\left(3 \times 10^{-3} \mathrm{M}\right)$ on taurine distribution ratio ${ }^{1}$

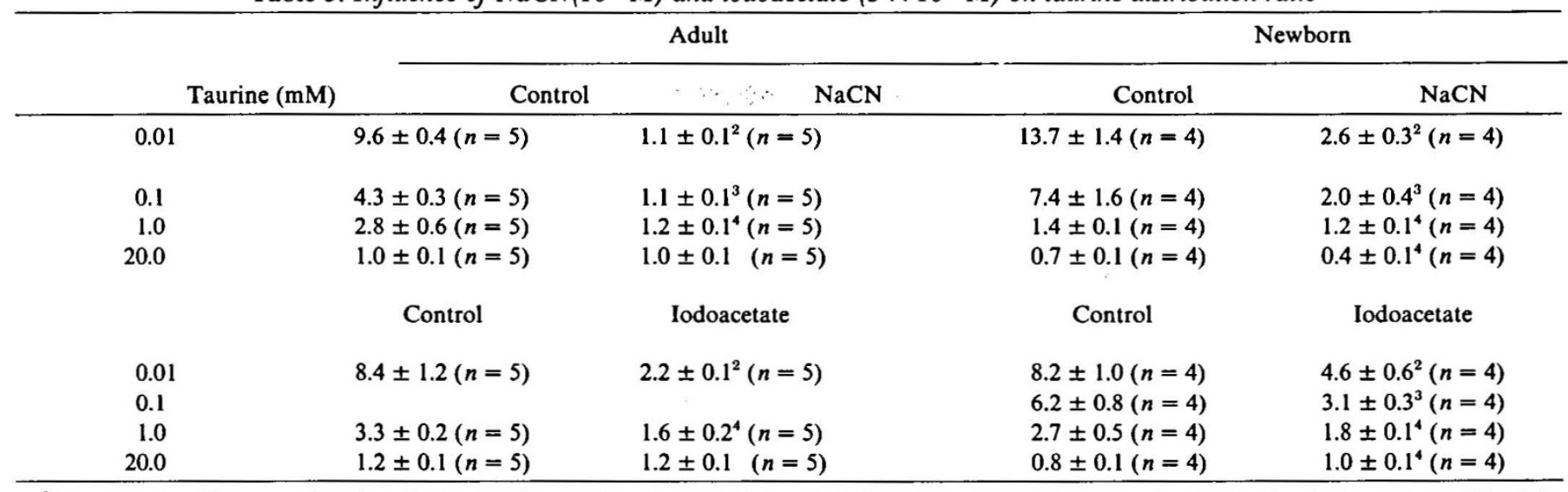

${ }^{1}$ Renal cortex slices were incubated with medium and taurine at $37^{\circ} \mathrm{C}$ and $\mathrm{pH} 7.4$ under $100 \% \mathrm{O}_{2}$ for 60 min. Each value is the mean $\pm \mathrm{SD}$ of the data $(n=$ No. of experiments).

${ }^{2}$ Difference is $<0.001$.

${ }^{3}$ Difference is $<0.02$.

${ }^{4}$ Difference is not significant.

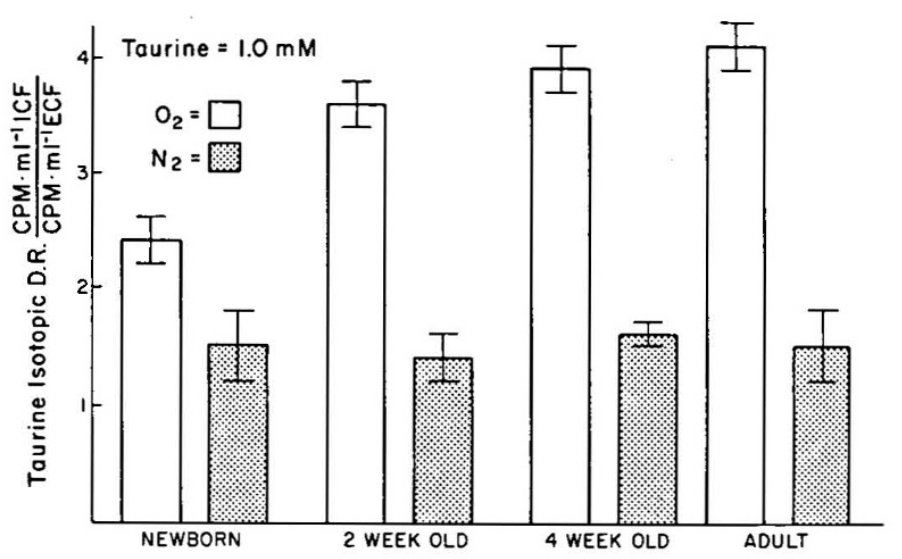

Fig. 6. The effect of anoxia on accumulation at an initial taurine level of $1.0 \mathrm{mM}$. Paired slices from the same animal were incubated either in oxygenated buffer at under $\mathrm{N}_{2}$ for $60 \mathrm{~min}$. Each bar represents the mean \pm SD of nine determinations. No age related differences in taurine accumulation are found and uptake is significantly higher $(p<0.001)$ in the presence of oxygen.

used in these steady-state experiments are probably not accurate indicators of uptake kinetics. Nonetheless, nonlinear plots were obtained in these studies, and there appeared to be evidence for more than one uptake system with different affinities for taurine found at each age studied.

Two findings could potentially explain the increased taurinuria of newborn and 14-day-old animals: First, differences in efflux and, second, in initial rate of uptake. As demonstrated for other $\alpha$-amino acids $(3-5,20,23,27,28,33,34)$, the rate of exodus of taurine from cortex slices of immature animals was reduced in comparison to that from adult slices. The in vivo level of taurine in slices from newborn animals was higher than that found in adult cortex, but the endogenous taurine concentration was not higher in slices from 2- and 4-week-old pups. Thus, backflux from an expanded pool would not be expected in 2-week-old animals. A possibly completely unrelated finding was that the initial rate of uptake was reduced in tissue from younger animals. Both these findings cannot fully account for the increased taurinuria of young animals because efflux was reduced and initial uptake rate was slower in slices from 28-day-old animals who demonstrate entirely normal taurine reclamation (6). As previously suggested (9), luminal brush border uptake may be decreased in immature animals. Studies are currently underway to examine the kinetics of taurine

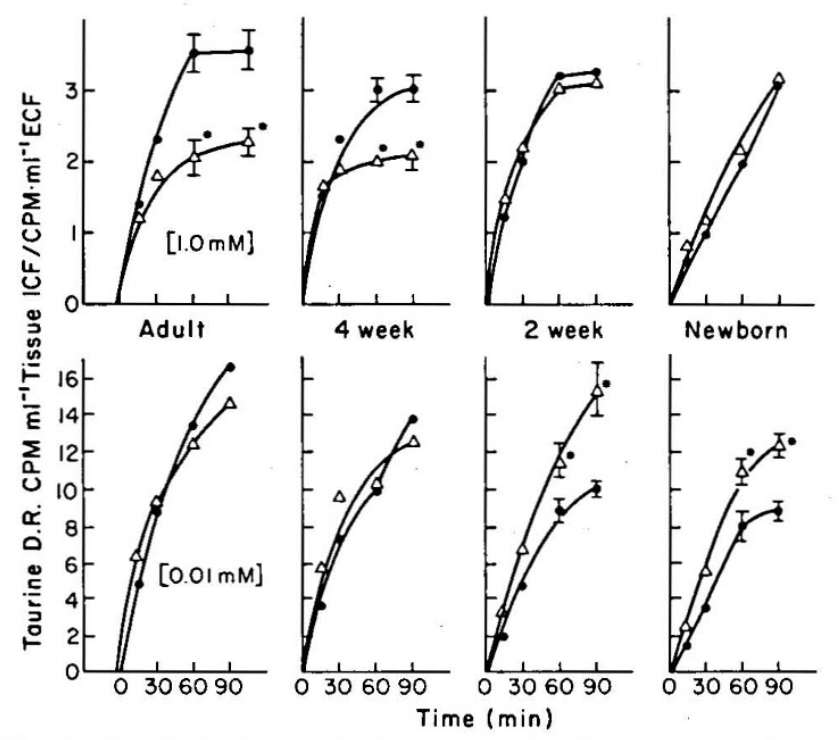

Fig. 7. The effect of preincubation on the rate of taurine accumulation by cortex slices. One-half the slices were preincubated in Tris-Ringer glucose medium ( $\mathrm{pH} 7.4$ ) for $120 \mathrm{~min}$ (open circles) and then transferred to flasks containing taurine at 0.01 or $1.0 \mathrm{mM}$ for incubation for the times shown at the ages noted. The other slices were incubated in taurinecontaining medium (closed circles) for the times shown. Each point is the mean of 12 determinations. The * indicates a significant difference from control values, $p<0.01$.

uptake by isolated membrane fractions where initial rate of uptake can be examined.

The dietary load of taurine and (presumably of cystine and methionine) presented to the rat pup changes over the first 4 weeks of life may have implications for the ontogeny or renal taurine transport. Even though taurine can be synthetized by newborn rat pups, Sturman et al. (31) have demonstrated that taurine is one of the most abundant amino acids in rat breast milk (26). The concentration of this sulfur-containing compound in breast milk fell during the first week of life and, thereafter, reached a constant level until the end of lactation at age 20-25 days. Sturman et al. (29) calculated that the actual dietary load of taurine probably varied less widely because older animals can ingest more milk: daily taurine intake varies from a mean of 1.7 mmoles/day immediately after birth to a nadir of 0.7 mmoles at age 7 days rising to $1.0 \mathrm{mmoles} /$ day at 10 days where it remains 

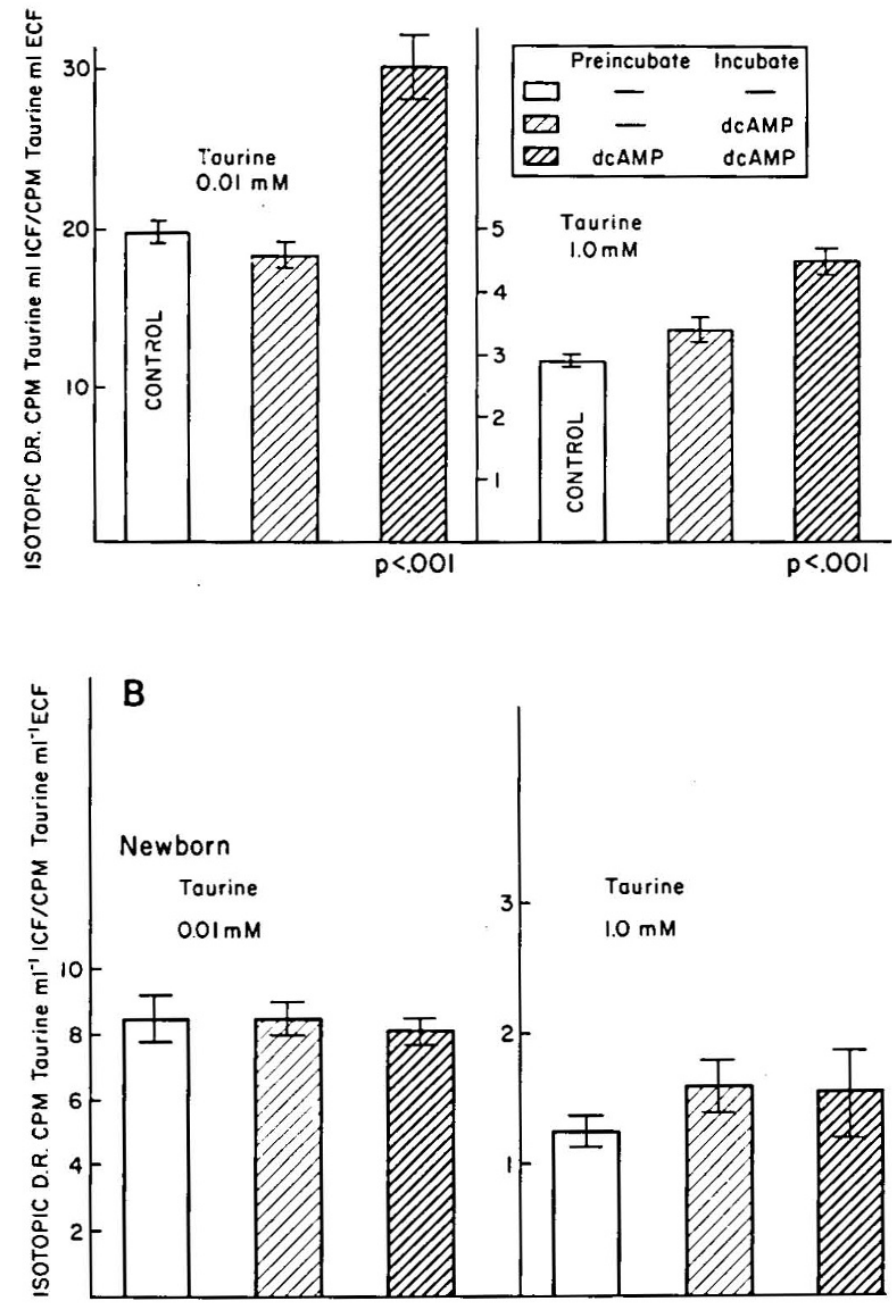

Fig. 8. The influence of dbcAMP on taurine accumulation by cortex slices from adult $(A)$ or newborn $(B)$ animals. Slices were preincubated in taurine-free medium for $120 \mathrm{~min}$ and then incubated in taurine containing medium for $60 \mathrm{~min}$ at $37^{\circ} \mathrm{C}(\mathrm{pH} \mathrm{7.4)}$. The dbcAMP concentration was 1.0 $\mathrm{mM}$ and the insert gives the code for each bar. Taurine uptake in adult tissue at 0.01 and $1.0 \mathrm{mM}$ is greater $(p<0.001)$ when tissue is both preincubated and coincubated with dbcAMP. No influence of cyclic nucleotides on uptake by neonatal tissue was found. Each bar represents the mean $\pm S E$ of 12 determinations.

until weaning (29). The high urinary levels of taurine could represent an overflow type of aminoaciduria from the large dietary load, but plasma taurine levels were not elevated in immature animals as would be anticipated in this form of aminoaciduria. The changes in dietary load after weaning were obviously dependent on the source of food, its methionine, cysteine, and taurine content and the amount ingested. However, the decrease in urine taurine content at age 28 days indicates that studies of the influence of dietary taurine load may be informative. We are currently investigating the influence of diet on taurine transport.

Sturman et al. have further shown that the turnover of taurine in liver and brain of immature rats is very slow (29-31). The specific activity of $\left[{ }^{35} \mathrm{~S}\right]$ taurine in rat brain did not change for at least 10 days after day 5 of life. The slow rate of uptake of taurine, the prolonged delay until steady-state was reached and the decreased rate of exit of taurine in renal tissue indicated that the turnover time in kidney cortex was also reduced.

The concentrative uptake of taurine in newborn kidney was somewhat partially protected from anoxia. Further, because sodium cyanide did not fully abolish uptake, anaerobic metabolism possibly accounted for this uptake. The energy responsible for taurine accumulation in the presence of iodoacetate which blocked glycolysis must remain speculative, but could represent the metabolism of endogenous fats or fatty acids. In contrast, concentrative metabolism under anoxic conditions or in the presence of $\mathrm{NaCN}$ was essentially abolished in tissue from adult animals. Baerlocher et al. (5) have described similar findings for proline and glycine accumulation. Whether this increasing dependence on aerobic metabolism with age represents maturational changes or has some adaptive advantage for the immature animal is unknown.

Enhanced uptake after preincubation in buffer at $37^{\circ} \mathrm{C}$ possibly indicated some functional adaptation of the transport systems of newborn kidney cortex which disappeared with maturation. This enhanced uptake was not the result of an altered exit rate and presumably represented increased uptake after preincubation so as to more nearly resemble uptake by adult cortex slices. This effect of preincubation could represent an increase in the number of transport sites or greater efficiency of accumulation, but further studies are needed to better answer this point. Only the first uptake system was affected by preincubation as was found for $\alpha$ AIB uptake in the studies of Reynolds and Segal (21). They found no change in the $\mathrm{Km}$, but an increase in the entry rate after this preincubation step which could be inhibited by cycloheximide, puromycin, and partially by actinomycin $D$.

Although cyclic nucleotides decreased the initial rate and steady-state accumulation of P-aminohippurate and uric acid by rabbit cortex slices (possibly by competitive inhibition) (18), dbcAMP increased the uptake of $\alpha$-AIB $(17,35)$, the sodiumdependent portion of lysine, glycine, arginine, proline, and leucine (35) and $\alpha$-methyl-D-glucoside accumulation (19). This effect of cyclic nucleotides is in distinct contrast to the situation in the intact animal where hyperaminoaciduria is found. The findings of Morris et al. (15) in the rat may explain this paradox; PTH and dbcAMP did not evoke aminoaciduria after thyroparathyroidectomy. Further, calcitonin administration resulted in decreased $\alpha$ AIB reabsorption in thyroparathyroidectomized Sprague-Dawley rats. Because dbcAMP can lead to increased calcitonin release, this hormone may be pivotal in the decreased amino reclamation of intact animals after cyclic nucleotide administration (13). Alternately, uptake across the antiluminal membrane may be differently influenced by these nucleotides.

Phang et al. (17) and Weiss et al. (35) found, as we noted with taurine, that preexposure to dbcAMP for at least $120 \mathrm{~min}$ was necessary in order to observe enhanced uptake. They found, in addition, that puromycin or cycloheximide could block this enhanced uptake. This influence of dbcAMP on taurine accumulation was not seen in renal cortex from neonatal animals suggesting that the response to cyclic nucleotides was a maturational change. The development of amino acid transport processes with maturation may possibly involve changes in the capacity of renal membranes to respond to cyclic nucleotides.

\section{REFERENCES AND NOTES}

1. Agrawal, H. C., Davidson, A. N., and Kaczmarek, L. K.: Subcellular distribution of taurine and cysteine-sulphinate decarboxylase in developing rat brain Biochem. J., 122: 759 (1971).

2. An-Huynh, V. A., and Fromageot, P.: Determination of exchangeable taurine in rat organs. Bull. Soc. Chem. Biol., 42: 221 (1960).

3. Baerlocher, K. E., Scriver, C. R., and Mohyuddin, F.: Ontogeny of iminoglycine transport in mammalian kidney. Proc. Natl. Acad. Sci., 65: 1009 (1970).

4. Baerlocher, K. E., Scriver, C. R., and Mohyuddin, F.: The ontogeny of amino acid transport in rat kidney. $\mathrm{l}$. Effect on distribution ratios and intracellular metabolism of proline and glycine. Biochim. Biophys. Acta, 249: 353 (1971)

5. Baerlocher, K. E., Schriver, C. R., and Mohyuddin, F.: The ontogeny of amino acid transport in rat kidney. II. Kinetics of uptake and effect of anoxia. Biochim. Biophys. Acta, 249: 364, (1971).

6. Chesney, R. W. and Jax, D. K.: Developmental aspects of renal $\beta$-amino acid transport. I. Ontogeny of taurine reabsorption and accumulation in rat renal cortex. Pediatr. Res., 13: 854 (1979).

7. Chesney, R. W., and Jax, D. K.: Heterogeneity of the $\beta$-amino preferring transport system in rat kidney cortex. Differential influence of glutathione oxidation. Biochim. Biophys. Acta, $466: 84$ (1977).

8. Chesney, R. W., Jax, D. K., Scriver, C. R., and Mohyuddin, F.: Taurine transport in mammalian kidney. In: A. Barbeau and R. J. Huxtable: Taurine and Neurological Disorders. p. 73-93 (Raven Press, New York 1978).

9. Chesney, R. W., Scriver, C. R., and Mohyuddin, F.: Localization of the membrane defect in transport of taurine by parallel studies in vivo and in vitro in 
hypertaurinuric mice. J. Clin. Invest., 57: 183 (1976).

10. Christensen, H. N., Hess, B., and Riggs, T. R.: Concentration of taurine, $\beta$ alanine, and triiodothyronine by ascites carcinoma cells. Cancer Res., 14: 124 (1954).

11. Gazzda, G. C., Franchi, R., Saibene, V., Ronchi, P., and Guidotti, G. B.: Regulation of amino acid transport in chick embryo heart cells. I. Adaptive system of reduction for neutral amino acids. Biochim. Biophys. Acta, 266: 407 (1972).

12. Gusseck, D. J., Yuen, P., and Longo, L. D.: Amino acid transport in placental slices. Mechanism of increased accumulation by prolonged incubation. Biochim. Biophys. Acta, $401: 278$ (1975).

13. McInnes, R. R., and Scriver, C. R.: Mechanism of the amino-aciduria produced by calcitropic hormones and dibutyryl cyclic AMP. Clin. Res., 22: 538A (1974).

14. Mohyuddin, F., and Scriver, C. R.: Amino acid transport in mammalian kidney: multiple systems for iminoacids and glycine in rat kidney. Am. J. Physiol., 219: 1 (1970).

15. Morris, R. C. Jr., McInnes, R. R., Epstein, C. J., Sebastian, A., and Scriver, C. R.: Genetic and Metabolic Injury of the Kidney. In: B. M. Brenner and F. C. Rector. The Kidney. p. 1193-1256 (W. B. Saunders and Co., Philadelphia 1976).

16. Neal, J. L.: Analysis of Michaelis kinetics for two independent, saturable membrane transport functions. J. Theoret. Biol., 35: 113 (1972).

17. Phang, J. M., Downing, S. J., and Weiss, I. W.: Cyclic AMP stimulation of amino acid uptake in bone and kidney. Biochim. Biophys. Acta, 211: 605 (1970)

18. Podevin, R. A., and Boumendil-Podevin, E. F.: Inhibition by cyclic AMP and dibutyryl cyclic AMP of transport of organic acids in kidney cortex. Biochim. Biophys. Acta, 375: 106, (1975).

19. Rea, C., and Segal, S.: Dibutyryl cyclic adenosine monophosphate enhancement of $\alpha$-methyl-D-glucoside accumulation by kidney cortex slices. Biochim. Biophys. Acta, 311: 615 (1973)

20. Reynolds, R., Roth, K. S., Hwang, S. M., and Segal, S.: On the development of glycine transport in rat renal cortex. Biochim. Biophys. Acta, 511: 274, (1978).

21. Reynolds, R. A., and Segal, S.: Regulatory characteristics of amino acid transport of amino acid transport in newborn rat renal cortex cells. Biochim. Biophys. Acta, 426: 513 (1976).

22. Riggs, T. R., and Pan, M. W.: Transport of amino acids into the estrogen-primed uterus. Enhancement of the uptake by a preliminary preincubation. Biochem. J., 128: 19 (1972).

23. Roth, K. S., Hwang, S. M., London, J. W., and Segal, S.: Ontogeny of glycine transport in isolated rat renal tubules. Am. J. Physiol., 233: F241 (1977).

Copyright $\odot 1979$ International Pediatric Research Foundation, Inc. $0031-3998 / 79 / 1307-0861 \$ 02.00 / 0$
24. Scriver, C. R., Chesney, R. W., and McInnes, R. R.: Genetic aspects of renal tubular transport: diversity and topology of carriers. Kidney Int., 9: 1491976.

25. Scriver, C. R., and Mohyuddin, F.: Amino acid transport in kidney heterogeneity of $\alpha$-aminoisobutyric uptake. J. Biol. Chem., 243: 3207 (1968).

26. Segal, S., Rea, C., and Smith, I.: Separate transport systems for sugars and amino acids in developing rat kidney cortex. Proc. Natl. Acad. Sci., 68: 372 (1971).

27. Segal, S., and Smith, I.: Delineation of cystine and cysteine transport systems in rat kidney cortex by developmental patterns. Proc. Natl. Acad. Sci., 63: 926 (1969).

28. Segal, S. and Smith, I.: Delineation of separate transport systems in rat kidney cortex for L-lysine and L-cystine by developmental patterns. Biochem. Biophys. Res. Comm., 35: 771 (1969).

29. Sturman, J. A.: Taurine in nutrition. Comprehens. Ther., 3: 59 (1977)

30. Sturman, J. A., Rassin, D. K., and Gaull, G. E.: Taurine in developing rat brain: maternal-fetal transfer of $\left[{ }^{35} \mathrm{~S}\right]$ taurine and its fate in the neonate. $J$. Neurochem., 28: 31 (1977).

31. Sturman, J. A., Rassin, D. K., and Gaull, G. E. Taurine in developing rat brain: transfer of [ $\left.{ }^{35} \mathrm{~S}\right]$ taurine to pups via the milk. Pediatr. Res., 11: 28 (1977).

32. Tennenhouse, A., and Quastel, J. H.: Amino acid accumulation in Ehrlich ascites carcinoma cells. Can. J. Biochem. Physiol., 38: 1311 (1960).

33. Weber, W. A.: A comparison of the efflux rate of AIB from kidney cortex slices of mature and newborn rats. Can. J. Phys. Pharmacol., 46: 765 (1968).

34. Weber, W. A., and Cairns, J. A.: A comparison of the amino acid concentrating ability of the kidney cortex of newborn and mature rats. Can. J. Physiol. Pharmacol., 46: 165 (1968).

35. Weiss, I. W., Morgan, K., and Phang, J. M.: Cyclic adenosine monophosphatestimulated transport of amino acids in kidney cortex. J. Biol. Chem., 247: 760 (1972).

36. Sprague-Dawley ARS, Fitchburg, Wisconsin

37. Sprague-Dawley rats from Holtzman Co., Madison, WI.

38. New England Nuclear Corp., Boston, MA.

39. Sigma Chemical Co., St. Louis, MO.

40. This research was supported by funds from the Univerity of Wisconsin Graduate School Research Committee, The Jessie E. Whitman Bequest and the National Institutes of Health, grant AM 19489.

41. Requests for reprints should be addressed to: R. W. Chesney, M. D., Pediatric Renal Disease Laboratories, The University of Wisconsin Center for Health Sciences, 1300 University Avenue, Madison, WI 53706 (USA).

42. Received for publication April 11, 1978.

43. Accepted for publication July $27,1978$. 